\title{
Un Cuento Inédito de Manuel Gálvez
}

Entre las treinta y una obras de ficción de Manuel Gálvez (18821962), figuran dos volúmenes de cuentos, Luna de miel y otras narraciones (1920) y Una mujer muy moderna (1927). Muchos de estos telatos aparecieron primeramente en Caras y Caretas, La Novela Semanal, $y$ otras publicaciones; $y$ fueron acogidos si no con el mismo caluroso aplauso que sus novelas, cuando menos con modesta aprobación. Los cuentos galvecianos salieron a la luz en el período de mayor vitalidad creadora del escritor, pero sus esfuerzos en este género siempre se relegaron a un lugar secundario respecto a sus novelas. En verdad, Gálvez tenía verdadera vocación de novelista, pero no más que un interés periférico en cultivar el cuento. En el transcurso de su larga carreta y ante técnicas narrativas mucho más atrevidas y originales, ha ido disminu. yendo la atención prestada a toda la producción de Gálvez. Pero lo que ya está olvidado casi por completo son sus cuentos.

Al fallecer Gálvez en 1962, dejó inéditas varias obras -novelas, recuerdos literatios, dramas - que su viuda se ha empeñado en publicar. Al enterarse ella de mi interés en la novelística de Gálvez, tuvo la gentileza de mandarme un mar de documentos, correspondencia, y materia biográfica y crítica. $Y$ también este cuento, que es el único que no ha sido publicado anteriormente. Según todas las apariencias, las páginas que me remitió la señora María Elena Gaviola de Gálvez son una copia al carbón del original tal como lo preparó el autor, excepción hecha de los tres últimos párrafos del cuento, escritos a mano por la propia viuda. Al final de "Esclavitud", la Sra. de Gálvez puso también con su letra "Octubre 18 de 1955", pero es muy dudoso que ésta sea la fecha de la composición. Lo más probable es que, a juzgar por la inmadurez estilís. tica y narrativa del relato, Gálvez lo haya redactado en su primera juventud, sacándolo del olvido muchos años más tarde, allá en octubre de 1955.

Los cuentos de Gálvez siguen la más simple fórmula narrativa. El único fin es referir una anécdota o serie de incidentes de la manera más 
directa y ordenada. Su arte cuentístico es quizás demasiado obvio y abierto. Sin pretensiones literarias, sin complejidades estructurales o verbales, su técnica huye de todo lo que no contribuya al movimiento lineal del relato. La sencillez estilística de "Esclavitud" es juvenil y defec. tuosa, pero en otras obras más logradas llega a ser una de las notas más características de su prosa. En cuanto al tema, "Esclavitud" no guarda ninguna relación con otros relatos, aunque el elemento de protesta social patente en el malhadado destino de la protagonista nos recuerda al Gálvez reformador de Nacha Regules e Historia de arrabal.

Digámoslo francamente, "Esclavitud" es uno de los cuentos de Gálvez menos logrados. El tema de la pobre muchacha campesina "dada" a otra familia por sus propios padres está débilmente desarrollado; resulta simplemente un esbozo superficial de un intenso drama que en manos más maduras pudiera haber sido una realización más feliz. La romántica idealización de sentimientos mezclada con la más penosa realidad es también otro rasgo común de la ficción galveciana. Pero a pesar de estos puntos de contacto entre "Esclavitud" y otras obras de ficción de Gálvez, el cuento no puede agregar mucho a su reputación y se ofrece aquí sólo como una adición a su vasta e importantísima bibliografía.

\section{Syracuse University}

Myron I. LICHTBLAU

"ESCLAVITUD": CUENTO DE MANUEL GALVEZ

La familia haragancaba en las piezas de la casa que corrían a lo largo del primer patio. El señor leía, en el escritorio, el diario de su partido político. El niño, en el comedor, iba y venía, tratando de aprenderse de memoria unos versos impresos en un libro que había puesto sobre la mesa y que miraba de rato en rato. La señora, en el cuarto de estar, pensaba. Las dos niñas se movían de un cuarto al o'to para embromar al hermano o para reírse de la abuela, que, en el cuarto de estar, sacaba solitarios. Era en pleno verano y hacía calor. En las piezas había esteras. $\mathrm{Y}$ todos vestían incompletamente, en mangas de camisa el papá y el muchachito y sin medias y en chancletas la madre y la abuela. $Y$ de lo alto de las puertas colgaban esteras, para impedir que entrase el sol. 
El sirviente, un criollo de pelo rizado, que calzaba alpargatas y venia de la puerta de calle, donde se pasaba las horas, llamó con las manos a la entrada del cuarto de estar.

- ¿Qué pasa, Trabuco?

- Acaba de llegar a caballo don Jerónimo, acompaña de una mo. renita que tiene aire de ser su hija.

-Que vengan acá y avisále al señor.

Oyóse en el patio de baldosas el ruido, seco y fuerte, de las espuelas de Jerónimo Valdemoros. $Y$ todos, para verlos aparecer, reuniéronse en el cuarto de estar.

La visita interesaba mucho a la familia. Jerónimo era un gaucho que vivía gratuitamente, a unas veinie leguas al sur de la pequeña capital de provincia, en un campito de don Cosme Salcedo, el dueño de casa. Jerónimo, que era caudillo en la comarca, podía contar hasta con doscientos gauchos, doscientos votos para las elecciones. Cuando en la ciudad se realizaba una manifestación de los opositores, uno de cuyos líderes era Cosme Salcedo, senador provincial, Jerónimo desfilaba a la cabeza de sus doscientos paisanos. Fidelidad de perro sentía por su patrón. Era un hombrón de espaldas formidables, cuerpo sólido, manos y pies enormes. Se movía con lentitud y miraba con una fijeza triste. Hablaba una que otra palabra, como con esfuerzo. Era muy moreno. Adoraba no sólo a Cosme sino a su mujer, Damiana, a las dos niñas, Rosa y Teresa, y a Juan Cosme, el muchachito de quince años. Decíase de Jerónimo que tenía "dos muertes", pero su bondad convencía de que fueron en defensa propia.

Jerónimo, que vestía bombachas y poncho, calzaba botas y llevaba unas enormes espuelas, dio la mano a Cosme y a los demás de la familia, sin pronunciar palabra, algo turbado y con el sombrero en una mano.

- ¿Y a qué se debe esta visita, Jerónimo? No te esperaba.

-El patrón se ha olvidao... ¿no ricuerda que le prometí darle a m'hija? Usté mesmo me la pidió. $Y$ aquí se la traigo. Esła es m'hija, po.

Todos miraron a la gauchita. Vestía una falda y una bata de percal, y llevaba trenzas y calzaba alpargatas. Era gordota y fea. Muy turbada, permanecía con los ojos en las baldosas. Traía un envoltorio en la mano, que debía ser de ropas.

— ¿Cómo te llamás? -le preguntó Damiana.

Tardaba en responder y hubo que repetirle la pregunta.

-Esclavitú... dijo ella poniéndose colorada.

Los tres niños rieron con estrépito. Cosme, que sólo había sonreído, 
los miró con enojo y les ordenó callar. A la muchachita, se le humedecieron los ojos.

- ¿Y de dónde sacaste ese nombre tan fierazo, Jerónimo?

- La madre se llama ansina, y lo mismo se llamaba la agüela, que en paz descanse. Pero no ej esatamente como contestó m'hija. Su verdadero nombre ej María de la Esclavitú.

Pocas palabras más hablaron. La edad de la gauchita, catorce años, sorprendió porque representaba más. Jerónimo iba a despedirse de $\mathrm{Da}$. miana y la abuela. Con la mano extendida, que Damiana demoró un poquito en tomarle, dijo:

-Doña Damiana, le entrego a m'hija. Cuídemela, señora, enséñele lo que necesita saber, trátela con dureza si no anda derecha y. . . No tengo más que decir. Don Cosme y usté, señora, son sus dueños. Hago esto por pobreza y por el bien de m'hija. Y también porque sé que ustedes necesitan a su lado gente buena, de confianza, que los respeten y quieran como a sus mesmos padres.

Esclavitud se llevó a los ojos un pañuelito. El gaucho se le acercó, la besó y le dio un abrazo, después de decir a los señores:

-Con permiso.

Cosme dijo que Esclavitud sería bien tratada, y agregó:

- Vamos al escritorio, Jerónimo, a conversar de nuestros asuntos.

Esclavitud entró en el cuarto de estar, rodeada de todos los demás de la familia. Damiana se repantigó en el sofá y, sin hacer sentar a la gauchita, se dispuso a interrogarla.

- ¿Qué sabés hacer? Contestáme, pues, hijita. No te voy a comer. Necesito que me digas para qué servís, qué sabés hacer...

-Es una taimada —opinó la abuela.

- ¿Qué quiere, mamá, que sepa —intervino Juan Cosme, ni se ha pasado la vida en un rancho?

Como no había modo de arrancarle una palabra, la señora dijo:

- Si nada sabés te enseñaremos. Aquí tenés que trabajar, no como en el campo, donde seguramente pasabas el día tumbada en la cama o sentada en una silla tomando mate. ¿Sabés lo que es ser "dada"? ¿No sabés? Pues quiere decir que pertenecés a tus patrones en alma y cuerpo y para toda la vida. No tendrás sueldo, porque no estás conchavada.*

* Conchavada: empleada. 
Sos dada. Podemos pegarte, mandarte al asilo si te portás mal. No podés protestar, ni irie de esta casa. Sos dada. Si te escaparas, te haríamos buscar y traer por la Policía. Ahora que sabés cuál es tu condición te mandaré al cuarto que vas a ocupar. Las sirvientas te enseñarán a lavarte y yo saldré a comprarte ropa, porque con esas mugres no podés andar.

Esclavitud apenas había levantado los ojos del suelo. Estaba asustada, terriblemente asustada. Todas las cosas que veía en el cuarto eran no. vedades para ella y la intimidaban tanto como sus patrones.

Damiana ordenó a una de sus hijas que tocara el timbre. Esclavitud, al oírlo, dio un salto. Rieron todos largamente. Apareció una de las sirvientas.

-Antes de que te vayás, quiero decirte que para vos el entrar en esta casa, y en condición de dada, es una suerte, es como sacarte la lotería. Vas a vivir bien. Comerás de todo, no sólo un zoquete, como allá en el rancho. Nosotros somos muy buenos, pero tenés que obedecernos, trabajar con gusto, no ser taimada, ni huraña.

La sirvienta se la llevó para adentro. Damiana salió a comprarle topa. Como la tienda quedaba enfrente, pronto volvió. La recibió la sirvienta con la noticia de que Esclavitud se negaba a darse un baño de lluvia. Allá fue Damiana.

- ¿Te gusta la roña, parece? ¿O tenés miedo porque tal vez nunca te has bañado en tu vida? No seas tan campiriña, tan bruta...

Esclavitud, con los ojos lacrimosos, aceptó. Y entró en el cuarto de baño, temblorosa y sollozando.

Así empezó en la casa de los Salcedos la vida de Esclavitud. Como nada sabía, ni siquiera cerrar una puerta, todos la insultaban. Damiana y las dos niñas la llamaban estúpida, gaucha, cerril. Le decían que parecía una vaca y le preguntaban si no estaba lela. Todo la asustaba. La primera vez, el día de su llegada, al anochecer, que vio encenderse la luz eléctrica, dio un grito. lo mismo hizo cuando oyó sonar el teléfono. Los demás se reían y burlaban de ella sin la menor compasión ni caridad.

Don Cosme era el único que no la trataba mal. Ella notó que Da. miana, delante del señor, no le pegaba ni la insultaba. Porque le pegaba, y lo mismo hacian la niña Rosa, de diecisiete años, y la niña Teresa de trece. Las dos niñas, de lejos, le sacaban la lengua, le hacían caruzas de asco o desprecio. La abuela solía darle consejos aburridores. Y el niño Juan Cosme, que no le pegaba ni se burlaba de ella, le tocó más de una vez la cara, al encontrarla sola.

Al principio, rompió, sin querer, algunos objetos: un plato, una taza, dos o tres copas. Damiana, a cada cosa que rompía, le propinaba 
un par de moquetes y la llamaba estúpida, bruta, atolondrada, y amenazábala con el asilo. Esclavitud aguantaba, aguantaba. Ni llorar podía. Cierta vez que se saltaron las lágrimas, la señora redobló la fuerza de sus moquetes.

Seis meses después del día de su llegada, todo en la casa se revolvió. Esclavi ud entendía sólo a medias lo que pasaba. ¿Qué podía entender ella de política y de partidos? Pero comprendió que su padre vendría al frente de doscientos hombres y se preparó para verlo. Desde la puerta de calle, en efecto, vio la manifestación opositora. En la primera fila, a pie, con otros señores, iba don Cosme, y detrás de los que marchaban a pie desfilaron los gauchos, Jerónimo adelante. Ella tuvo una honda alegría, aunque apenas translució. Le tiró un beso con la mano a su Tata y él levantó el rebenque.

Esto fue por la tarde. Al rato de acabarse la manifestación, se presentó en la casa su Tata. Ya había llegado el patrón, muy contento. Los señores estaban en la mesa. Jerónimo fue al fondo, para darle un beso a su hija, y después se encerró con don Cosme, en el escritorio. Parece que los gauchos se habían vuelto y sólo quedaba en la ciudad Jerónimo, que pensaba alcanzarlos. Cuando se fue era ya de noche.

Al otro día, llegó la horrible noticia. Jerónimo, al pasar por un puente, había sido baleado y muerto por policías del Gobierno. Le habían esperado detrás de unos árboles. Conmovido, don Cosme le dio la noticia a su hija y él, a caballo, se dirigió al rancho de Jerónimo, a donde ya habían llevado el cadáver. Días crueles pasó Esclavitud por esa desgracia. Otra vez se volvió muda. Todos creían que no había sentido la muerte de su padre. Sólo Juan Cosme, al encontrarla sola, le había dicho:

— ¡Pobre! Me das lástima...

III

Con la muerte del padre, la situación de Esclavitud empeoró. El trágico suceso, y $\tan$ repentino, la puso tremendamente nerviosa. Aumentó la rotura de platos, copas y tazas. Sus patrones no veían, sin embargo, tal nerviosidad y atribuian los destrozos de torpeza, a estupidez congénita, cuando no a venganza porque la habían amonestado o infligido un par de cachetadas.

No la dedicaban a servir la mesa por temor a una catástrofe. Su tra. bajo consistía en lavar los patios, el cuarto de baño y el dormitorio de Juan Cosme. También pasaba una o dos horas diarias aprendiendo a leer 
y a escribir y estudiando el catecismo. Ni siquiera sabía rezar, excepto el Padre nuestro. Cuando se enteró Damiana de la ignorancia de la infeliz, la llamó salvaje y otras cosas.

-Es imposible que tu madre no te haya enseñado algo de religión, a menos que sea una imbécil. Seguramente vos no aprendías porque no tenés caletre, ni querés aprender nada. Debés saber que en esła casa somos buenos cristianos. Trataremos de enseñarte aquí mismo. $O$ te mandaremos a la doctrina los domingos por la tarde. Si no fueras dada no me importaría tanto, aunque los patrones deben ocuparse de que sus sirvientes sean buenas cristianas. Peto sos dada, es decir casi como de la familia, y yo respondo ante mi conciencia y ante Dios de que no permanezcás en estado salvaje.

Como Esclavitud siguiera callada, en pie, delante de la señora, Da. miana le gritó:

- ¿No me das las gracias, siquiera, por lo mucho que me desvelo por vos? ¿No ves que estoy preocupada por la salvación de tu alma?

Esclavitud movió los labios. Sin duda quiso decir "gracias, señora", pero las palabras se le atracaron y no salieron afuera.

- Sos una desgraciada, una perversa - la insultó Damiana, que se levantó furiosa y le dio un fuerte bofetón.

Durante unas semanas, Esclavitud pareció con enta. $Y$ lo estaba en efecto. El catecismo le hacía mucho bien, sea por la enseñanza en sí misma, por lo que iba aprendiendo de Dios, o porque en la doctrina conocía otras muchachas como ella, con las cuales conversaba.

- ¿Cuánto ganás? -le preguntaban las demás sirvientas.

- Soy dada. . - - respondía Esclavitud sencillamente, como si el serlo fuera algo corriente y natural.

Como ya llevaba unos meses en la casa, parecía un poco despabilada y conocía el valor de los billetes y moneditas, alguna vez la mandaban a comprar algo al almacén, o a la farmacia, o a la ferretería. Retornaba con los ojos menos apagados y con una expresión que pudiera ser un principio de contento.

Pero un día le ocurrió una catástrofe. Se cayó contra uno de los vidrios de una puerta, un vidrio de más de dos metros de altura, y lo rompió. Don Cosme, que estaba presente, experimentó un atrebato de cólera, se abalanzó hacia la desgraciada y le encajó tal puñetazo que le ensangrentó la nariz.

- Te tuve consideración mientras vivía tu padre, pero ahora no estoy obligado a tenértela. Sos verdaderamente una canalla. Te complacés en hacernos daño. 
Esclavitud se fue a su cuarto. Una de las sirvientas, que era compasiva, le puso árnica y la consoló.

-Es el señor, tiene derecho, sos dada...

-Ya sé, ya sé... El tiene derecho hasta de matarme. Pero yo espero que en la otra vida... lo pasaremos mucho mejor...

Esclavitud sufría y se conformaba. Estaba resuelta a soportar los golpes y las humillaciones. Pensaba en esto, cuando entró la cocinera, una vasca española.

-Dime tú ¿y vas a aguantar la cochinada que te han hecho?

- Soy dada...

- Qué dada ni qué demonios! Ya no hay tales dadas. Ni el patrón ni nadie tiene derecho a pegarte. A mí, si me tocara un pelo, te juro que le rompía la cara. ¡Atrayúa! Por el momento, no debes trabajar, y no por lo que te duela sino como protesta. Como protesta, sí, sí.

Esclavitud, impresionada por el consejo de la vasca, dijo que no trabajaría. Su cuartucho estaba sobre la cocina. Se negó a bajar. Esperaba, de un momento a otro, que la señora viniese a sopapearla o a insultarla. Pero nada ocurrió ese día ni esa noche. A la mañana, la señora le mandó decir que hiciera un paquete con su ropa y que bajara. ¿Qué iba a pasar, Dios mío? ¿La echarían a la calle? ¿Y qué haría ella por ahí, sola en el mundo? Se acordó del empleado de la farmacia, del hijo del ferretero y de otro muchacho, que la habían mirado de una manera... Porque había dejado de ser la gordota de hacía unos meses. Ahora estaba pasable y tenía unos labios rojos y unos ojos negros que...

-Te llevo al Asilo — soltóle, sin preámbulo, Damiana-. Es adonde llevan los patrones a las sirvientas rebeldes y que se portan mal. Allá te enseñarán las hermanas a andar derecha.

Y la empujó para que fuese adelante.

\section{IV}

Las hermanas del Asilo no la trataban mal. Por el contrario, eran buenas y consideradas. Pero no le permitían libertad ninguna. Entre ellas y otras que habían hecho cosas muy feas, no existía diferencia. Durante dos meses no vio la calle, y la calle era su esperanza y su placer.

Ahora podía pensar. Desde que llegó a la casa de don Cosme vivió como asonsada, como embrutecida. Pareciale tener nubes dentro de la cabeza. No entendía nada de nada. El miedo y el respeto la volvían muda, paralizaban sus movimientos. $\mathrm{Ni}$ con las otras sirvientas podía hablar. 
Era natural, por consiguiente, que todos la mirasen como una bruta. Cuando quería pensar en su situación le venía una especie de mareo. Ni veía, siquiera. Si le preguntase cómo era la cara del señor o de la señora no sabría qué contestar. No las habia mirado a esas personas. ¿Por qué? Sería por temor de ofenderlas, o por creerse ella una cosa de nada, una hormiga, o por saberse propiedad de ellas.

Desde que estaba en el Asilo, aunque como una presa, veía todo con un poco de claridad. Le abrumaba esa palabra "dada", que le parecía terrible. Era dada, dada... Habían dado su persona entera y su alma, y también su vida, al señor Salcedo y a la señora. Eran dueños de ella, y lo mismo que eran dueños de sus vacas y de sus caballos. Pero ella ¿sería tan poquita cosa como una vaca? ¿No tenía un alma? $Y$ su vida ¿no era de Dios? El catecismo le hacía pensar, y en él hallaba cosas que no se avenían con su condición de dada. Le habían enseñado que todos éramos iguales, hijos de Dios. Pero ella, una dada, una pobrecita dada, no era igual a nadie, ni a las otras sirvientas, y apenas si era igual -iy todavía quién sabe! - a una vaca.

Y sus padres ¿por qué la habían dado, "regalado" a otras personas? ¿O la habían vendido, tal vez? ¿Y tenían derecho para dar una hija como se da un perro o una gallina? No comprendía... Cierto que allá en el rancho había mucha gente: el padre, la madre, tres hermanas, un muchachito. Era también cierto que no tenían cómo comprar ropa y otras cosas. Carne no faltaba. En el campito había muchas vacas. Pensaba que tal vez su padre quiso quedar bien con el patrón. ¡Lo quería tanto a don Cosme! A ella le parecía que la miraba como a Dios. Don Cosme, según contaba su padre, se había quejado en varias ocasiones del mal servicio, de las chinitas insolentes que no sabían hacer nada ni tenían moralidad y de yapa exigían sueldo... Sí, eso debía ser. Pero... ¡dar una hija, regalarla! ¿Y podría venderla? Si era él su dueño, seguro que podría venderla... Y al pensar esto, Esclavitud soltaba el llanto.

A los dos meses se apareció la señora. La mandaron llamar. En la sala donde recibían las hermanas a las visitas la encontró con la superiora.

- ¿Cómo te va? Ya sé que te has portado bien. Fue una inspiración de Dios encerrarte aquí.

- Yo creo que se quiere quedar - dijo la superiora. ¿'Tengo razón?

$\rightarrow$ No, madre. Quiero irme.

-Pero afuera, en el mundo, se sufre...

-Y bueno... Yo quiero sufrir, quiero vivir. .

Esto de que Esclavitud quisiera vivir no le gustó a la señora, que le decretó otro mes de Asilo. "Otro mes de prisión", pensó la muchacha. 
Estaba resuelta a seguir soportando la vida en el Asilo, pero una de sus compañeras de prisión la invitó a escaparse juntas. Petrona tenía bien arreglada la escapatoria, y una noche abandonaton el Asilo. Revuelo entre las hermanas y las asiladas. Se avisó a la casa de don Cosme y a la Policía, para que la buscase y las trajese de nuevo al encerradero. Don Cosme y Damiana bramaban de rabia. Les parecía que Esclavitud había cometido el más grave de los delitos. La abuela se pasó el día entre suspiros y exclamaciones: "¿Qué cosa, Señor, si parece mentira!" Las dos niñas decían improperios de la dada.

- iY que me haga esto una hija de Jerónimo, de un hombre que hubiera dado la vida por mí! ¡Desagradecida, perversa! ¿No la hemos tratado bien, como a una hija? La hemos vestido, le hemos dado de co. mer, le hemos enseñado a rezar, le hemos también enseñado a trabajar. Si la echáramos a la calle, que es lo que se merece, podría conchavarse y ganarse un sueldito con lo que en mi casa ha aprendido. ¡Mala gente, ralea vil!

En el pueblo la noticia de haberse fugado del Asilo dos mujeres corrió rápidamente, y cuando se supo que una de las "criminales" era una "dada" que pertenecía a don Cosme, fueron visitas como a darle el pésame. $\mathrm{Y}$ don Cosme hablaba de Esclavitud, delante de las visitas, igual que en su casa.

A la noche comunicó la Policía que las prófugas habían sido halladas. Como no era tarde, Cosme y Damiana fueron al Asilo. No quisieton ver a la desagradecida. Cosme le dijo a la Superiora:

-Queremos que sea castigada severamente y que se quede aquí dos meses más.

- La tendremos a pan y agua una semana - suspiró la Superiora.

-Es poco -afirmó Damiana-. Por lo menos, deben tenerla encerrada quince días y a pan y agua.

- Sus deseos, señora, serán cumplidos. Todo sea por amor a Dios.

\section{V}

Esclavitud, desde su retorno del Asilo, fue tratada peor que antes. Ahora no la mandaban nunca a la calle, fuese por castigo, fuese por temor de que se escapara. Y trabajaba el doble y no la enviaban a la doctrina.

El señor no está en la ciudad. Lo habían hecho diputado y se había ido a Buenos Aires. Le contaron las sirvientas que la familia se instalaría allí en abril o mayo del año siguiente. 
- ¿Me llevarán? -les preguntaba Esclavitud.

-Se me pone que no - le contestaba la que servía la mesa.

- ¿Y qué van a hacer de mí?

- iVaya una a saber! A lo mejor, te dejan en el Asilo.

- Si hacen eso, me mataré.

Como no estaba el señor Cosme, la señora se aprovechaba para castigarla por cualquier insignificancia. La abuela parecía, en ocasiones, querer calmar a su hija. Las niñas la ofendían de palabra desde la mañana hasta la noche. También la hacían ir de un lado para otro de la casa, por fastidiarla, pidiéndole cosas. Si ella se equivocaba, le decían:

- ¿Cuándo vas a dejar de ser una guasa, y volverte gente?

-Sólo el niño Juan Cosme era bueno con ella. Nada de particular le decía, pero la miraba con lástima. Era compasivo, el niño. Una vez que la señora le pegó brutalmente por haber roto la sopera, el niño le reprochó a la madre:

-Basta, mamá. Es un ser humano...

Desde entonces, Juan Cosme le dirigía casi diariamente algunas palabras. Esto ocurría por las mañanas, muy temprano. El niño había que despertarlo a las seis y llevarle el chocolate a la cama. Los demás lo tomaban después de las ocho y media. Una vez, el niño le dijo:

- Me da vergüenza que sean mis padres y mis hermanas ¡Cómo te tratan, pobrecita!

-Cuidado, niño que lo pueden oír -le rogó ella, con la voz tomada y con lágrimas.

Pero no podrían oír porque estaban lejos. El dormitorio de Juan Cosme era la última de las piezas y estaba en el segundo patio, después del cuarto de baño.

A Esclavitud las palabras del niño la hicieron dichosa. Por fin encontró un alma que la compadecía. Ya no estaba tan sola, tan espanto. samente sola. Y comenzó a pensar en el niño Juan Cosme. A él también lo maltrataban sus padres. Muchas veces, el señor le daba una cachetada. Otras, lo dejaban sin el postre, o sin comer. Debía ser muy bueno el niño, para compadecerse de una pobre "dada" como era ella. No com. prendía que a él le pegaran. Era su hijo, al fin y al cabo. A ella sí, sobre ella tenían derecho porque su padre se la dio al señor Cosme, se la regaló...

Por las mañanas, cuando entraba en el cuarto del niño, sentía emoción. Acercábasele con la bandeja y lo miraba dormir. "¡Pobrecito!" pensaba, llena de lágrimas. Se quedaría una hora contemplando su sueño, su cabeza despeinada. En varias ocasiones, lo vio destapado, y maternalmente, 
le subió las cobijas. Por fin, lo llamaba. El, al despertarse, la miraba y le decía:

- ¿Dormiste bien anoche? ¿Has amanecido dispuesta a seguir aguantando?

-Por usted, niño... - le contestó ella una vez-. Si no existiese usted, me mataría.

-No, eso nunca - le dijo él conmovido y tomándole una mano y besándosela.

Cuando Juan Cosme cumplió dieciseis años los padres, las hermanas y algunos parientes le hicieron regalitos. Al otro día, al llevarle el chocolate, Esclavitud le dijo.

-Niño, yo hubiera querido regalarle algo, pero soy la persona más pobre del mundo. Ni cinco centavos tengo...

- Me podés hacer el mejor de todos los regalos.

- ¿Yo? Dígame cuál es, niño...

-Darme un beso...

- Con toda el alma, mi niño, aunque es demasiado honor para mí, para esta pobre dada.

$\mathrm{Y}$ se unieron las bocas en un largo beso. $\mathrm{Y}$ al día siguiente día hubo otro beso, y otros besos trajeton caricias. Y una mañana, él la atrajo a su cama y la poseyó.

Dos semanas después, partieron todos a Buenos Aires.

\section{VI}

Se instaló la familia en una casa vieja de la calle Cerrito. Como las sirvientas no quisieron venir del pueblo, fue preciso buscar otras. Escla. vitud se enteró de que les pagaban treinta pesos a esas muchachas y cuarenta a la cocinera. Las tres mujeres eran españolas. Y como a ella le preguntasen cuánto ganaba debió confesarles que ni un solo centavo, porque era "dada".

- ¿Dada? ¿Y qué es eso?

-Y... que mi Tata me dio al señor don Cosme. No soy libre. No me puedo ir de aquí. Trabajo de balde, porque soy como de la familia.

La reacción de las tres compañeras fue distinta. Una de ellas se in. dignó contra el patrón, que era un canalla, y también contra ella que aceptaba ser esclava. Una de las sirvientas se echó a carcajadas, y se pasó el día repitiendo esa palabra "dada", con sarcasmo, humildando así a la obre campiriña. La otra, más humana la aconsejó; 
- Mira, chica, tú tienes que irte, dejándolos que rabien. Tenemos que averiguar. Creo que en este asunto debe intervenir el juez de menores. No podemos permitir esta explotación.

Pocos días después, el patrón llamó a Esclavitud. La hizo entrar en su escritorio, y, con la mayor solemnidad, le dijo:

-En adelante, y aunque no lo merecés, vas a ser libre. Te pagaré de sueldo cinco pesos mensuales. Si te portás como la gente, pronto ganás el doble o el triple. Te aconsejo no gastarte el dinero. Guardálo, porque alguna podrás enfermarte y tendrás gastos de médico y de remedios.

- Gracias, señor -contestó ella, emocionada.

-Pero esto no significa —agregó don Cosme- que podás irte así no más. Te hemos hecho muchos servicios. Nuestro médico te ha atendido varias veces, y te hemos pagado remedios, ropa y zapatos. En realidad, era como si ganaras cuarenta pesos mensuales. $Y$ sin contar que te dábamos gratuitamente la casa, la comida, la luz y otras cosas. Por consiguiente, debés estarnos agradecida. Si te fueras, te haría traer.

¿Qué había pasado? Juan Cosme lo supo. Un hermano de su padre, hombre de espíritu liberal, se había escandalizado al saber que don Cosme tenía una "dada". Le había dicho que eso era practicar la esclavitud. Si los diarios enemigos se enteraban, se lo dirían. $Y$ tal vez algún diputado.

-Yo no vengo más a verte - le dijo - si mantienes en tu casa esa esclava. Es una barbaridad ¡hombre! Si allá en el pueblo se hace, aquí no se puede hacer. Esta es una ciudad civilizada.

La situación, pues, había cambiado para Esclavitud. La trataban con rabia, le hacían desprecios, pero no le pegaban. Los domingos, si las otras dos sirvientas no salían, ella podía hacerlo. La primera vez que se encontró sola en la calle, experimentó terror. No sabía a dónde ir. Por la calle Cerrito bajó hasta Cuyo y siguió hasta Florida. Todo le asustaba. Un hombre le echó un piropo y apresuró el paso para escaparle. Se le ocurrió que podían raptarla, o asesinarla. Volvió a la casa muy cansada y con las piernas flojas. Había oído hablar a las otras sirvientas de unos hombres que robaban mujeres y después las encerraban en casas malas, para vivir a costa de ellas, de la prostitución de esas infelices. Le horrotizaba pensar que ella pudiera ser una víctima de esos hombres perversos. Sentíase indefensa, y hasta pensó que era mejor ser "dada", porque el parrón la defendería, ya que, además de diputado, contaba, de seguro, con la polecía y con las leyes. Pero los miedos y sustos pa- 
saron pronto, y entonces ella se puso contenta y sintió el orgullo de no ser ya "dada", el orgullo de tener libertad, de ser dueña de su vida.

Desgraciadamente, vino un suceso, o, mejor dicho, la consecuencia de un suceso, a perderlo todo. Creía volverse loca y le desespetaba no poder contar a nadie su desgracia. Volvió a su mutismo absoluto de otro tiempo, a su ensimismamiento, a no darse cuenta de nada, a su distracciones. Hasta que por fin, no pudiendo soportar un día más su soledad, se lo dijo a Juan Cosme.

—Qué calamidad tan grande! —exclamó el niño—. Yo no pensé en esto. Soy un canalla. Perdonáme...

- No, niño, usted no es un canalla. La culpa es de los dos. Lo triste será que tengamos que separarnos. Yo me iré, me echarán...

- ¿Y a dónde vas a ir? Yo le pediré plata a papá.

Hablaban en el dormitorio de Juan Cosme, mientras se enfriaba el chocolate. El muchachito, en su aflicción, se echó a llorar. Dijo que hablaría con el médico de la familia, para que Esclavitud pudiese entrar en un hospital. $\mathrm{Y}$ después, se conchavaría en otra casa, tendría un buen sueldo...

Esa tarde, Damiana se puso a observar a la sirvienta. $Y$ como la infeliz enrojeciera, la agatró de un brazo y le preguntó:

- ¿Estás en estado, sinvergüenza? Eso te faltaba, ser una grandí. sima... Así nos pagás, deshonrando a esta casa honrada. Pero aquí no te vas a quedar. Las niñas pueden enterarse, y ellas no deben saber que existen en el mundo estas porquerías. Hoy mismo te mandarás mudar. No quiero degradadas en mi casa.

-Y exclamó, teatralmente:

- ¿Qué hemos hecho, Señor, para que así nos castigues?

Esclavitud permanecía con la cabeza baja y largas lágrimas corrían por su rostro.

- ¿Y quién es el sinvergüenza que te ha hecho ese mal? Hay que saber el nombre. Le exigiremos que se case con vos. Tiene que remediar su delito. Porque es un delito, siendo vos una menor. Decíme el nombre del canalla, ahora mismo, te lo mando... ¿No querés hablar? ¿Te has vuelto muda, o sos una taimada? Hablá, cochina...

-No diré su nombre ni aunque me maten.

- iAh, ah! ¿Y no querias casarte tampoco, ni siquiera por tu hijo? ¿No pensás que tu hijo no tendrá un apellido?

-No quiero casarme.

Damiana le hizo diversas fechorías: le pegó en la cara, le tiró de los cabellos con fuerza, la pellizcó cruelmente, la sacudió con violencia. 
Después, tocó el turno a don Cosme. En el escritorio se teprodujeron los insultos y los golpes. También él insistía en saber, y ella en negar. Por fin, el señor bajando la voz, le preguntó:

- ¿No será Juan Cosme, eh? Se me ocurre que él ha de ser. Decíme la verdad. Yo también he sido muchacho y todos los hombres somos más o menos sinvergüenzas... Confesá que es mi hijo... ¡Chiquilín vivo, con una hembrita a su edad! Te daré plata si declarás que es él. No me enojaré iqué esperanza! ¿Y por qué me había de enojar? Es él ¿cierto?

-No es él.

Por cierto que, al otro día, Esclavitud no le llevó el chocolate a Juan Cosme. En la sospecha de que el adolescente fuese el culpable, Cosme y la señora resolvieron que no viese más a la sirvienta. Le habian dado un día para buscarse otra colocación. Pero a la tarde, y como ellos se andaban buscando, fácilmente se encontraron.

-Te pegaron, no? Yo oí por la cerradura los insultos de mi madre, y te vi salir, llorando, de la conversación con el viejo. Quería verte para decirte que... sólo yo tengo la culpa...

- Si dice eso, niño, me mataré. Esté seguro de que me mataré.

- ¿Por qué? No hay motivo para que hagás esa barbaridad...

-Usted no puede quedar mal, niño. Su tata y su mama se enojarán y después, se sabrá que tiene un hijo... y que la madre del hijo vive... Y por eso, no se podrá casar. . No, niño, quiero que se calle. Le prometo que nadie sabrá nada... Si habla, me mato, me mato, niño.

La infeliz había hablado entre sollozos. Oyóse ruido en el cuarto vecino.

-Viene alguien - le dijo él-, andáte, buscaré otra ocasión de hablar. .

No pudieron volver a verse. $\mathrm{Ni}$ esa noche ni a la mañana siguiente. La sirvienta lo despertó con el chocolate.

- ¿Y Esclavitud?

- Se ha ido, niño, hace un rato.

- ¿A dónde? -exclamó Juan Cosme, como el rostro demudado... $¿$ No sabés a dónde?

-No sé nada, niño.

\section{VII}

Dos días después, a la hora que convinieron, Juan Cosme estaba en la plaza.

Aguardó un cuarto de hora, media hora, tres cuartos de hora. ¿Le habría sucedido algo? ¿Se habría enfermado? ¡Y él, sin saber en dónde 
vivía! Considerábase un estúpido por no habérselo preguntado. Pensó en que tal vez ella le escribiese. Era posible que por abnegación no quisiera verlo más. Pero él la buscaría por la calle. Perdería muchas tardes hasta encontrarla. $Y$ afligido de amarguras y de conatos de llanto, se encaminó, convertido en un deshecho humano, hacia la pensión.

Por la tarde, salió en busca de su amiga. No la halló por ninguna parte. Pero al otro día, leyó en el diario una espantosa noticia: en su cuarto de mujer de mala vida había sido encontrado el cadáver de una muchacha joven, que parecía llamarse María de la Esclavitud Valdemoros. Se había envenenado con arsénico. Había dejado una carta abierta en la que decía: "Me mato para no estorbar en su carrera al joven estudiante a quien adoro. Yo no merezco vivir. Total, no he sido sino una pobre dada y sin derecho siquiera para querer y ser querida."

Octubre 18 de 1955

MANuel Gálvez 